Exploring doctoral students' use of digital technologies: what do they use them for and why?

\author{
Anastasia Gouseti \\ School of Education and Social Sciences, University of Hull, UK \\ Cottingham Road, HU6 7RX, Hull, UK \\ $+44(0) 1482466358$ \\ a.gouseti@hull.ac.uk
}

Word count (main text): 8,044

This work was supported by the LEAP Directorate, University of Hull under the 2015 ISL Scheme (award number not applicable as funders do not use one). 


\title{
Exploring doctoral students' use of digital technologies: what do they use them for and why?
}

\author{
Digital technologies now form an integral feature of the university student \\ experience and there is a range of studies that explore digital technology use \\ within a higher education context. However, very few of these studies focus on \\ how doctoral students engage with digital technologies. This paper aims to throw \\ light on the digital practices of doctoral students and advance understandings of \\ the changing nature of digital scholarship for them. Drawing on qualitative, in- \\ depth interviews with twelve PhD students in a UK higher education institution, \\ the paper identifies seven distinct types of engagement with digital technologies \\ and discusses the range of issues that underpin doctoral, digital scholarship \\ practices. Furthermore, it argues that although the stereotypical portrayal of the \\ $\mathrm{PhD}$ as a 'lonely journey' is seen to be in decline, doctoral students at large exist \\ and work 'in a vacuum' rather than within interactive doctoral communities.
}

Keywords: doctoral students; digital technologies; digital scholarship; online communities

\section{Introduction}

Acquiring research skills and conducting empirical research are key elements of doctoral education. At the same time the PhD journey also involves developing critical thinking, producing high-quality written work as well as negotiating new identities as a researcher and forming sustainable networks. The stereotypical image of the 'academic hermit' (Dunleavy 2014) or the 'lone scholar' that used to epitomize the idea of an academic researcher is seen to be in decline and so is the portrayal of the $\mathrm{PhD}$ as a 'solo journey' (Lee and Danby 2011). Policy shifts in the UK have juxtaposed this conventional model of study with a more collaborative one that is based on doctoral students' interaction and collaboration and involves engaging in non-thesis related activities (Pilbeam and Denyer 2009). Amongst having a range of more traditional skills such as looking for and managing a range of resources, thinking critically and creating 
new knowledge, conducting high-quality, ethical research and so on, doctoral students are increasingly expected to interact and support each other's learning, provide peer feedback and share understanding and expertise. Students are also expected to acquire networking and team-working skills by developing and maintaining departmental as well as external networks with other scholars (QAA 2015). This is seen to be important not just for their development as doctoral students but also for their future career progression as Early Career Researchers (ECRs).

As such there is a shift from more structured approaches to doctoral education towards the implementation of more 'open and flexible' attitudes (Cumming 2010). Furthermore, empirical research in the field has highlighted that increasingly doctoral students are not relying solely on the mentoring of their supervisors but they are also learning within multiple communities of practice where peers can be seen as important ‘learning partners’ (Flores-Scott and Nerad 2012). participating

At the same time, digital technologies now form an integral feature of the university student experience. Different tools can be employed to facilitate students with various aspects of their learning journey and developing digital literacy competencies is seen to be a vital part of the student journey. According to the JISC digital literacies framework (2014 n.p.) that applies to students of all levels of further and higher education 'digital literacy looks beyond functional IT skills to describe a richer set of digital behaviours, practices and identities’ (JISC 2014, n.p.). In particular this framework encompasses a range of capabilities that can be supported by diverse technologies and may differ across particular contexts. As such, elements of digital literacies that are particularly pertinent to studying at doctoral level are ‘communications and collaboration' e.g. taking part in digital networks for learning and research; 'career and identity management 'such as being able to manage your online 
identity; and ‘digital scholarship’, that is, participating in academic and research practices that depend on digital technologies. Furthermore, digital literacy is perceived by Beetham and Sharpe (2010) as a development process where students can progress from simply accessing digital technologies and acquiring functional skills to developing higher level capabilities and forming an online identity. To this end, within a doctoral context students can be seen to be engaged in an on-going development process that begins with access and functional skills and aims to reach higher-level capabilities and identity development.

Although digital technology use might be integral to the work of all students in the late 2010s and is shaping their academic practices, doctoral students have different requirements as they are expected to develop higher-level capabilities and engage in different practices compared to those of other students at different levels. In particular, according to the VITAE (2011) Researcher Development Framework IT literacy and competency in using information and digital technology is seen as an essential attribute of doctoral researchers within the domain of knowledge and intellectual abilities. Additionally, collaborating and communicating research 'virtually' and using eresources are important attributes within the domain of engagement, influence and impact.

Recent literature has also adopted the term 'digital scholarship’ to describe a range of scholarly activities that are afforded and influenced by the use of new technologies (Weller 2011). These can involve conducting research, teaching and collaborating as well as 'embracing the open values, ideology and potential of technologies born of peer-to-peer networking and wiki ways of working in order to benefit both the academy and society’ (ibid, 50). Similarly, Veletsianos (2016, 2) adopts the term 'networked scholars' to describe doctoral students as well as academic staff 
who 'make use of participatory technologies and online social networks to share, improve, validate, and further their scholarship'. As such there appears to be significant overlap between the characteristics of digital scholarship and the expectations of doctoral level work and doctoral students' attributes according to the QAA and VITAE framework. This involves to a large extent higher-level digital capabilities and distinguishes doctoral students’ digital practices compared to, for instance, undergraduate students’ engagement with digital technologies.

Notably, despite the abundance of research on digital technology use within a higher education context (see Edmunds, Thorpe, and Conole 2012; Goodfellow and Lea 2013; Henderson, Selwyn, and Aston 2015; Valentín et al. 2013), very few studies have focused on doctoral students' digital practices. Additionally, existing research that has explored the impact of digital technologies on the changing nature of academic practices and the shift towards digital scholarship has at large focused on established or early career academics (Costa 2014; Lea and Stierer 2011; Stewart 2015; Veletsianos and Kimmons 2013). Other studies have adopted the term scholar more broadly to refer to individuals who participate in teaching and/or research endeavours (e.g. doctoral students, faculty members, instructors, and researchers) (Veletsianos and Kimmons 2012). However, there is a growing need for more research that explesores the similarities and differences in digital technology use between students and faculty members (Veletsianos and Kimmons 2016).

Notwithstanding the rich literature available on the general doctoral experiences and issues of doctoral identities (Mantai 2015; Pilbeam, Lloyd-Jones, and Denyer 2013; Baker and Lattuca 2010; Barnacle and Mewburn 2010), there is a rather small body of literature that looks at how $\mathrm{PhD}$ students engage with digital technologies during academic trajectories. For instance, the recent 'Researchers of Tomorrow' large-scale 
study that looked at the information-seeking practices and research behaviour of doctoral students born between 1982 and 1994 as well as older doctoral students reported that at large doctoral students are sophisticated information-seekers and competent users of complex information source (JISC 2012). However, they tend not to be early adopters or keen users of the latest technology applications and tools in their research but only use applications that can be easily absorbed into their existing work practices. Additionally, they are more cautious towards the use of open web and other web 2.0 technologies that may challenge their more traditional research working practices (ibid).

Similarly, Esposito (2014) in her study of PhD students at Italian and UK universities found that they endorsed a more cautious approach towards digital technology use when focusing on academic activities. In particular it was reported that doctoral students' digital engagements tended to be pragmatic rather than pioneering and they relied on tools that made research practices more straightforward. It was only a small minority of $\mathrm{PhD}$ students that had a more active presence on social media sites such as blogs and Twitter as opposed to the larger majority who relied to traditional networking channels such as seminars and conferences (ibid).

Other examples of empirical research in the field focus on part-time doctoral undertaking distance learning degrees. For these part-time Computing students who took part in the longitudinal survey, technologies were largely selected based on recommendations from peers and they tended to mix and match the tools to suit supervisory practices. Different technologies were employed within academic and personal contexts by students and a growing need for training and mentoring on digital professionalism and managing an online identity was highlighted (Petre, Minocha, and Barroca 2014). 
PhD students were also reported to use new tools such as blogs, Facebook and Twitter to support scholarly communication practice, disseminate their work to a wider audience and gain feedback, and promote their academic profiles (Zhu and Procter 2012). Other research in the area has found that time and commitment requirements as well as the lack of incentive were seen by doctoral students as barriers towards the effective use of social media for supporting research practices, developing team working skills and building sustainable networks (Coverdale, Hill, and Sissons 2011).

With these in mind this paper aims to enable insight into how doctoral students engage with digital technology use for their academic studies. In particular, the paper will now consider the following research questions:

- What types of digital technologies do doctoral students use for their academic studies?

- What types of practices do they engage with?

- What are the factors that affect their choices and practices?

\section{Research Methods}

These questions were addressed through a small-scale exploratory study that was conducted during the autumn term of 2015. The research involved individual, semistructured, in-depth interviews with twelve home and international doctoral students studying both full- and part-time at a higher education institution in the UK. The university is a public, research-intensive institution and is considered one of the 'old' universities in existence before 1992. All participants were enrolled in a research doctorate, a $\mathrm{PhD}$, rather than a professional doctorate study and they were at different stages of their PhD. They were all pursuing a $\mathrm{PhD}$ in the field of education. Of those 
interviewed four were in their second year, three were in their third year and five were at a writing-up stage. Only two students were part-time and three were home students whilst the other nine were international students from a range of countries. There were seven female and five male participants and they all came from different age groups ranging from mid-twenties to early fifties. All in all, although this study is not making claims that this a representative sample, the group represented a range of geographical areas, heterogeneous cultures and different age groups. Once ethical approval was gained from the Institution, an email was sent out to all PhD students at the Faculty informing them of the research study and inviting them to take part in the interview. As such, a self-selecting sample of twelve students participated in the study in the end.

The interviews which lasted between 40 and 70 minutes, were audio recorded and then transcribed verbatim. For the purpose of this paper, a pseudonym was assigned to all participants so as to guard their anonymity. Thematic content analysis was employed in order to analyse the data. This involved initial readings of the interview transcripts to familiarise oneself with the data and to generate initial codes and themes. These were then reviewed before the emerging themes were finalized and the interview transcripts were coded in NVivo. The following abbreviations will be used for interviewees’ excerpts: Year (Y), full-time (FT), part-time (PT), International (INT), Home (H).

\section{Results}

The students were asked to describe the digital technologies they used during their doctoral studies, to explain the different types of practices they engaged in and to identify any existing enablers and barriers relating to digital technology use. The interview data gave valuable insights into what doctoral students were using the technologies for and highlighted a range of pertinent issues. In particular, seven 
distinctive digital practices were identified and will now be discussed in more detail.

\section{Utilising online tools to research information}

One of the most prominent practices described by the students was related to using digital technologies to research information in their area of study. In particular, they used the online library databases as well as other websites such as Google Scholar in order to carry out research for their chosen topic. Interestingly, students valued the availability of digitized resources such as eBooks and electronic journals accessible through the library. The majority of students relied primarily on electronic resources for their research rather than using hard copies of books and journal papers. This allowed them to adopt 'remote' modes of studying, annotate and retrieve the electronic documents easily and store everything on their devices as opposed to carrying hard copies around. For example as one of the student described:

\footnotetext{
It [the use of digital technologies] has affected how I communicate, how I disseminate information, how I store my information, so I don't have shelves filled with books and I don't think, after my first year, I didn't maintain the articles anymore, I didn't need to print any articles, because I have folders and folders of articles that I downloaded from the databases. I don’t go to borrow books so much, because I can read most of them online (Nadine, Y4, FT, INT).
}

\section{Managing and storing content}

An equally prevalent practice cited by the majority of students was using bibliographic software such as EndNote, RefWorks etc for storing and managing references and generating bibliographies. Only one student reported that she had chosen to compile her bibliographic references the 'old- fashioned way' with the use of a Word document. The use of bibliographic software was described as providing a number of advantages 
relating to saving time, easily retrieving references and creating bibliographies at the click of a button:

I've got my document up on the screen, my journal article up on the screen, and I can just go to site export or into Ref Works and it does it for me...so that database and the ease of just pressing site export has been an absolute lifesaver...yeah, that's been absolutely fantastic for me (Rio, Y2, PT UK student).

Storing and managing content was also supported by the use of cloud-based file hosting services. Dropbox and Google Drive were used by the majority of students while OneBox and iCloud as well as the university network drives were also mentioned but to a lesser extent. The benefits of using such tools were at large related to safe storage and backing up of resources and data and to a lesser extent to synchronization of content across different devices. Interestingly, one of the students described how she used different cloud-based hosting tools to differentiate between personal/lifestyle content versus academic resources:

In my One Drive I can store the electronic books, papers and I can write some paragraphs like $\mathrm{PhD}$ journals every day when I read something interesting or something which is helpful in my PhD project [...] I always use Dropbox to store my data from - data of the EndNote and this is just for EndNote and the more comprehensive information about my PhD project and yeah the Google Drive is just for the lifestyle things. (Shuan, Y2, FT, INT).

File-sharing practices were less common. Only two students mentioned that they used cloud-based hosting tools to share documents with their supervisors and another student described how he had used Dropbox to collaborate with other researchers for a coedited research journal:

When I did the mobile learning journal, it was co-edited with a German guy, so everything was done by Dropbox, you know, all the editorial lists of contents and 
the editing and the uploading of different ideas and maps and things, so everything went through Dropbox there (Rob, Y4, FT, H).

\section{Collecting, managing and analysing data}

Another frequently cited practice was the use of computer software packages for qualitative and quantitative data management and analysis such as NVivo and SPSS. The benefits of using such tools were at large associated with ease of organisation, analysis and saving time:

I use the NVivo programme which is very useful and is very quick. It's better than doing manually because I did that in the Masters Degree and it is taking huge time (laughs) (Zaida, Y3, FT, INT).

One student mentioned how she had experimented using Google Voice to transcribe her interview data but with poor quality results and she had then used a transcription software:

I'm using this one, Express Scribe Transcription software...It's a very good one and you can download for free and it will like slow down the speed of the interviews so that you can hear and write down in a very effective way (Liu, Y3, FT, INT).

Interestingly, the majority of students were encouraged by their supervisors to adopt the use of data analysis computer software and they reported that during supervision meetings they would bring their own device to share and discuss their analysis and findings with their supervisors.

Only one student adopted a more traditional content analysis approach that involved physically cutting and pasting interview transcripts into large sheets of paper and then created relevant Word documents. However, as she described: 
In hindsight I feel from now on when I continue to do my research I will use NVivo...It was such a long process and there were times when I was going back, I mean it certainly helped me to get to know my data really well, but now I wish that I had all of those themes and these categories particularly because obviously you have some data that fits into more than one category and theme (Kate, Y4, PT, H).

Digital tools such as online surveys were also used for conducting quantitative research. Moreover, many students described how they used tools such as the WhatsApp messenger to communicate with their research participants.

\section{Communicating with supervisors and peers}

Email was the primary tool used by all research participants for communicating with supervisors, sending them completed work and receiving feedback. Students also reported that the majority of supervision meetings were conducted face-to-face whilst the use of Skype was a commonly used communication tool, albeit to a lesser extent and mainly used when either the students or the supervisors were away from campus. There were fewer instances of using a wider range of tools to facilitate doctoral supervision and these were recounted by students with a research focus on educational technologies. In particular, one student reported '[having] all of the supervisory records in Dropbox, and so that's shared with both supervisors' (Jessica, Y4, FT, INT) whilst another student reported receiving feedback in the format of a podcast that was shared through Google Drive (Adnan, Y5, FT, INT). Communication with fellow PhD students mainly took place through email, phone and mobile messaging applications such as WhatsApp and less often through social media tools such as Facebook.

\section{Engaging in formal and informal and peer learning}

Practices related to informal learning were frequently reported by the majority of participants. In particular, one of the most prominent student practices was watching 
videos on YouTube to support and complement formal learning. For instance, a lot of the international students found doctoral training courses informative and helpful but they often felt they needed extra support. This usually took the shape of watching YouTube tutorials on a range of areas- most notably data analysis and bibliographical software. The benefits students mentioned included learning at their own time and pace and overcoming language barriers by being able to replay the videos at their convenience. As one student described:

The person who was responsible to deliver the course [NVivo] he’s speaking fast [...] he speaks to someone like he is an expert like him, so I couldn't understand many things from that. That's why I depend on YouTube, so that is easier than attend any lectures here in the library [...] to be honest, it is easier to go to the YouTube because you can listen many times. You can stop everything, that's the easiest thing (Basel, Y2, FT, INT).

Watching YouTube videos and accessing non 'academic' resources such as websites also allowed students a 'smoother' introduction and transition to challenging concepts and areas such as theoretical frameworks and research paradigms:

For example to say how to do the way of literature review for example, I can go to You Tube and a website for example to get much understanding what does it mean, beside going to the library (Hariz, Y2, FT, INT).

Conversely, one mature international student reported how his lack of 'self-learning' skills as well as his lack of confidence to explore digital technologies more had affected his digital literacy skills and to some extent his academic studies:

In my culture- especially my generation - we don't have like what you call self learning, usually we go to class and the teacher have the book [sic] and we do exams. It's not like here to learn the skills. So I think that affected me badly now. I miss the self confidence, that's the most important thing. If I have self confidence I will be involved more and more in the technology (Omar, Y4, FT, INT). 
Tellingly, digital practices explicitly related to formal learning were reported less frequently. This at large included accessing module resources on the VLE as well as accessing information through the online library catalogue and Google Scholar.

Digital tools were also seen to facilitate and support peer learning. This ranged from the sharing of useful resources and good practices to providing support and guidance with particular tools. As one student explains:

I use Facebook when I use the NVivo programme because sharing ideas with people and asking questions and raising some problems - this is kind of helping you develop your knowledge. I don’t think just learning from the book or learning from training by yourself is enough; you're sharing the idea with other people, it is helping you to develop your mind (Zaida, Y3, FT, INT).

\section{Creating online academic identities}

Although studying for a PhD formed a large part of the participants' identity, this was not widely reflected in their online practices. The majority reported having personal social media accounts, which were shared with friends and family. However, a very small number of students had an online academic presence. In particular, three out of the twelve doctoral students actively used Twitter for academic social networking. Other students had registered for websites such as academia.edu, ResearchGate and LinkedIn but they mainly used these to follow other academics in their field rather than promote their own research and network or take part in online academic discussions and offer advice. The majority of students especially those in their earlier doctoral stages explained that they had little input to make and they felt less confident to engage in such practices due to their relatively low position in the academic hierarchy:

I'm not comfortable right now to give advice because I have not proven anything yet so far, right? So basically especially in Asian country at least our tradition, our culture basically, you finish your $\mathrm{PhD}$ at least because people say, "Oh he 
completed his $\mathrm{PhD}$ ” so at least - your advice, people will appreciate compared at this moment (Hariz, Y2, FT, INT).

The students who used Twitter and other social media more actively were aware of how they managed parallel digital identities and how these developed over time, and they were keen to have boundaries between their professional and personal lives:

It is pretty straightforward for me in that Twitter is my professional space and Facebook is more personal where I'll maybe do things about my family or something. So I'm aware of it. I don't think it's hard as such but I'm aware of the identities that I'm projecting now (Jessica, Y4, FT, INT).

Interestingly the three students (two international and one home) who had developed a more active online presence through social media had aspirations to get employment in academia in the UK upon the completion of their $\mathrm{PhD}$. As one of the research participants at the final stages of her $\mathrm{PhD}$ comments:

I don't think you can survive without knowing all this [...] because recently I have looked at job applications, and they are asking for your presence in social media, your academic profile, your research profile. And those are quite evident in places like ResearchGate and Twitter, where you have a proper professional profile, and those organisations can easily access it (Nadine, Y4, FT, INT).

However, these three students had also completed their data collection and were in the final ‘writing-up’ stage of their $\mathrm{PhD}$ and this could have also been another contributing factor towards developing an online identity and disseminating their research through social media.

\section{Participating in doctoral communities and scholar networks}

Independent thinking and learning is a highly valued skill for doctoral students on their journey to becoming experts in their chosen field and making their distinctive voices 
heard. Although independence does not have to be translated into operating alone without any support and guidance, it can lead to a sense of isolation. This can especially be the case if there are limited opportunities for doctoral students to socialise and interact with peers through modes of formal and informal study such training courses, seminars, reading groups, etc. As one student describes:

Because all the students, they're just working on their own, depend on their own to solve all their problems and everything, yeah. This is the strategy I think that is used here. Yeah. Just to solve your problems alone, yeah? (Laughter) (Basel, Y2, FT, INT).

As such, the majority of students seemed to de facto perceive studying at doctoral level as a lonely journey. As one student contends 'I think in a PhD it's quite typical to work in a kind of a vacuum really’ (Rob, Y4, FT, H). As reported in the interviews, none of the research participants felt they were part of a Faculty- or University-based community of doctoral students. Instead, they talked of 'acquaintances' or they discussed how they 'knew of' other students in a similar field (Liu, Y3, FT, INT). This is also reinforced by the fact that the majority of postgraduate research training modules were centrally offered by the University's Graduate School and the Library and did not necessarily offer opportunities for interacting with researchers from the same research field.

This sense of lack of belonging was also mirrored in the absence of an online Faculty- or University-based doctoral community. As one of the students explained:

Physically I don’t have a community but there’s no digital community either. So it's mirrored in a way, it's not like there is this active digital community and nothing on the ground. I kind of feel like there's nothing on the ground and there's nothing in the digital space either [...] I'll come [to research seminars] and then you always see new faces or familiar faces as well. But you come together but then that's it there's not really any way to carry on even that conversation 
afterwards, and I don't find that there's a lot of other people Tweeting about what we're doing there... (Jessica, Y4, FT, INT).

Despite the lack of a wider doctoral community and their accounts of long-hours work in isolation, the majority had formed friendships with a few fellow $\mathrm{PhD}$ students from their own or other Faculties. These friendships and informal peer support networks were often based on shared cultural backgrounds and countries of origin and students found great value in these. As described earlier email, phone and mobile messaging were the most favoured communication tools for peer communication.

Although findings suggest that networking is not a top priority for doctoral students particularly those in the earlier stages of the PhDs, the majority did engage in some kind of scholar network. Engagement in scholarly networks predominantly consisted of two different practices which sometimes overlapped. The first one involved ‘following' established academics in social networks such as Twitter and discovering new people within their research field. This allowed them to advance their research interests and find out about relevant events and recent academic publications in more social or purposeful ways by 'following' academics in their field or by searching for relevant hashtags:

I’m following many experts in LinkedIn and Twitter, like my supervisor he tweets many times about education and technology and I read most of his tweets and sometimes re-tweet his tweets (Adnan, Y5, FT, INT).

Scholar networks also took the shape of sustaining contact with people students had met during face-to-face events and activities such as conferences. Participation in such online affinity spaces was seen a meaningful way to sustaining their contacts and promoting their own research: 
I found it [Twitter] was a way to stay connected with people. I've presented at many conferences, and you always meet people there and that's a way to keep that active, and also occasionally there will be two or three people who are active Tweeters. So if you're presenting and suddenly they're Tweeting about you, and then that's exciting and so you want to be within that network because they're promoting this... And then I can support them so it's a little bit of relationship building and networking in the digital space (Jessica, Y4, FT, INT).

Interestingly, international students reported being involved in scholar networks and communities that were active in their native language and they used these as a primary source of receiving and offering support as well as sharing knowledge.

This is academic group, this is a specialist group and we have - in Malaysia we call that "Doctoral Support Group” [...] it's not formal, we just share - if anyone got problem, need a help, we share knowledge and everything, we're passing through using the emails for example (Hariz, Y2, FT, INT).

Furthermore, international students often used digital tools such as Facebook or WhatsApp groups to connect with pre-existing friends and acquaintances also studying in the UK and form support networks.

Some of them I know them before I come here, and others I have known them here in UK and of course we help each other. We are like a community, you know? (Basel, Y2, FT, INT).

Last, one particular student who was active on Twitter described how she followed hashtags such as the \#phdchat and reported that she experienced a sense of belonging there:

People express themselves, how they feel, people ask questions, others answer. When people achieve, people go and do their vivas, and they talk about their successes, everybody comments so it is quite a community. As a researcher, as somebody who is doing a research degree, sometimes you feel the only way to get some support is online, and so that is what is driving me (Nadine, Y4, FT, INT). 
Conversely, another student described how although he was an active participant in online academic communities on Twitter he felt engagement was rather superficial:

We look at things and we sort of deal with things on a very cursory superficial level. And we comment on something and we think, "There's a lot more to talk about there”. So they're not deep communities, they're not deep networks. I think they're quite vulnerable actually and insecure and they're content based, but the ideas are never fully explored (Rob, Y4, FT, H).

\section{What affects students' choices and practices?}

Having explored the distinctive digital practices that were identified from the interview data, this section will now go on to explore in brief the factors that affected students' choices and types of engagement. The findings indicate that the majority of participants took the guidance given by their supervisor(s) as the starting point for the digital tools they adopted to support their studies. This guidance predominantly involved the use of data analysis and bibliographical management software:

My second supervisor as well, she is very digitally inclined, so I have to follow suit, yes. But it is fine, because I do enjoy, it is an opportunity for me to learn because these skills are required eventually, by the time I finish my PhD (Nadine, Y4, FT, INT).

Students' choice of tools was also affected by their peers who did not only make recommendations but also offered guidance and hands-on help.

One of my friends, he is crazy about these technologies things, he is expert in this area and he helped me to establish an online Cloud to store all of my PhD materials so that in that way if my computer broken down and my data will not lost, so currently I put all my files, all my writings, on the Cloud (Liu, Y3, FT, INT). 
As such, peer support and learning emerged as a significant factor underpinning engagement with digital technologies whilst awareness of new tools and new ways of using tools was often facilitated by peer networks.

\section{What are the barriers and challenges underpinning digital technology use?}

For the majority of international students their doctoral studies presented them with considerable challenges in terms of literacies and modes of research and scholarship both online and offline. For instance, students from Arab states and Asian countries were accustomed to more traditional, teacher-centred approaches to learning and their prior experiences with digital technologies were more limited:

Of course the lecturer produces everything, he is the only speaker in the classroom and students just, they are listening to the teacher taking notes, sometimes just asking questions, but we don't use other teaching technologies like visual aids or something like that. We really find, of course, lack of these things [sic] (Basel, Y2, FT, INT).

Moreover, students highlighted dissimilarities across countries with regard to communication practices and academic expectations. Email use, for instance, which is so widely used in academic communication practices in developed countries, was seen as a novelty by some of the international students:

When I came to England in 2006 I didn't have email address. When I came here I found that the email address is the most important thing; you have to have an email, that's what they told me. So that's my beginning with email, I can't remember at that time how old I was, 35 years old or more? Wow I missed all that! (Omar, Y4, FT, INT).

Prior access to and familiarity with digital technology was also seen a significant factor that underpinned student practices and was linked to their level of confidence. For 
instance, for many international students digital technologies had not been an established part of their lives prior to their doctoral study:

I still remember I asked one of the staff, 'Do you have any typewriters in here?' and she laughed, 'We haven’t had any typewriters for ten years!' Well in my country, in my office we are still using typewriters because that development is not provided, the office has one old PC. This is an example to show the gap between my country and practice in the UK (Hariz, Y2, FT, INT).

Notwithstanding these barriers, the majority of students embraced the new ways that technology could support their doctoral studies, they were open to the use of new tools and sought training opportunities offered by the institution and the library services in order to improve their digital skills. In particular, they described how they were trying to overcome their lack of confidence as well as the technical challenges they faced. However, as one international student explained, changing her digital habits was viewed as a continuous and ever-evolving process not something that could be achieved from one day to the other.

\footnotetext{
I think it has changed very gradually and very slowly because I think the style or the techniques that people use when they study is like a habit [...] It's like for example I have to learn to use EndNote but at first we have to change our habit from past, so it's not always very comfortable for us to change it, but I'm happy to accept it because sometimes I love some technology things to help me study, so I can change it but I think the process is a little bit slowly [sic] (Shuan, Y2, FT, INT).
}

The lack of physical spaces dedicated exclusively to $\mathrm{PhD}$ students in the Faculty was often perceived as an important barrier to developing a sense of belonging that could initiate physical communities, which could also develop an online presence. The room available to $\mathrm{PhD}$ students at the Faculty was not favoured as it was very limited in space and desk/computer availability and not accessible late in the evenings and during 
weekends.

I don't think there is a space that I can come to, because I'm teaching as well I often put in days, like I come in on Saturday’s and Sunday’s for example, to do my work or I would like to stay later on some days. And [the PGR room in the Faculty] isn't suited for that, and so I tend not to do anything here which also means that I don’t know the new incoming students, I don't know who's here (Jessica, Y4, FT, INT).

Another important finding was how doctoral students perceived the notion of openness which is becoming more and more central in academic digital scholarship practices. The majority were rather cautious of sharing their research and they placed limits on how much they could disseminate prior to passing their Viva. There was a delicate balance between seeking peer support and feedback from face-to-face and online communities and being careful of 'over-sharing' research findings through routes other than conferences/seminar presentations and journal publications. As one student describes:

We need to be very cautious of putting anything about our research which has not been published on the web because that would involve a lot of confidential issues, so maybe that's why I don't feel like get myself involved too much of these social media things, because most of my research is unpublished I am just working on that, so if I get these things onto website I don't know maybe whether other people will see them and might be use, misuse them (Liu, Y3, FT, INT).

\section{Discussion}

The study presented here aimed at exploring doctoral students’ digital practices and developing a better understanding of the issues underpinning these practices. The findings confirm that digital technologies are an embedded feature of doctoral scholarship. Doctoral students reported that they used a wide array of technologies in their studies and they were involved in a range of tasks during their research trajectories. These included seeking new information, collecting and analysing data, 
writing-up as well as disseminating their findings and networking and this study has shown that digital technologies clearly played a significant role in most of these activities.

Doctoral students’ digital practices predominantly included rather ordinary types of engagement such as researching information through online resources and catalogues, digitally storing and managing bibliographic references, using computer software for data collection and analysis and backing up work on cloud-based hosting services. Engaging in informal learning by watching online video tutorials and also engaging in peer learning by interacting with other students face-to-face or via email and social media tools were also prevalent digital practices. These findings were supported by the JISC (2012) study which reported that doctoral students found the use of social media and other applications helpful in retrieving and managing research information whereas the use of digital tools for collaboration and scholarly communication was less widespread.

The findings of this study point towards a clear shift from paper-based research practices to the use of online resources and digital tools. It can be argued that students' academic practices were to some extent responding to an era which is embracing the move towards paperless resources and where scholarship is increasingly seen to be more digital (Weller 2011). This wider use of digital technologies was associated with the ease and usefulness of annotating, storing, managing, retrieving and manipulating digital content as well as the portability of the digital resources and is in line with the findings of a large-scale survey on undergraduate students’ perceptions of useful digital technology (Henderson, Selwyn, and Aston 2015).

The use of portable devices such as laptops and to a lesser extent tablets was central to all students' accounts of academic practices. Even for campus-based students 
the portability of the devices was seen as a particular advantage as they tended to use spaces other than their accommodation to study. As such, the portability of the devices as well as the availability of digital resources allowed them to be less bound by place. Although studying was not restricted to institutional premises, doctoral students placed great value on the availability of physical spaces. Full-time students, in particular, cherished study spaces and computer rooms specifically allocated to doctoral students as this allowed them to socialize with peers. This is in line with James et al. $(2009,1)$ findings who reported that '[p]hysically proximate relationships are currently dominant in the lives of many ECRs'.

All participants were aware that academic research communities are becoming increasingly accessible through the web and they were familiar with the range of dedicated platforms and social media tools they could use to create an online presence and a professional profile in line with the QAA (2015) and VITAE (2011) expectations of doctoral level attributes. In particular, a small number of students employed digital tools and platforms such as Twitter and blogs to distribute their doctoral identities across different domains or contexts. However, the majority of these students at large tended to follow the work of more established academics with only three out of the twelve students using their academic Twitter account more actively by contributing content and promoting their own research. This echoes the findings of other studies which highlight that the use of digital technologies and in particular social media by doctoral and post-doctoral researchers tend to be localised and dispersed rather than consistent and widespread (Research Information Network 2010). Additionally, echoing the findings of the JISC study $(2012,50)$ the majority of students took 'a fundamentally cautious personal approach to sharing their own research'. 
Also of note were findings relating to the $\mathrm{PhD}$ seen as the individual endeavour of the 'lone scholar' versus a shift toward the idea of creating and nurturing networks. Despite policy efforts to promote more networked and collaborative practices between doctoral students, the majority reported that they tended to work in isolation for the best part of their studies. This appears to be in line with the findings of Pyhältö, Stubb, and Lonka (2009, 221) who reported that about one third of the $602 \mathrm{PhD}$ students 'did not perceive themselves as being members of any scholarly community at all'. The JISC (2012) study also reported that a feelings of isolation are common in doctoral research. As Mantai $(2015,9)$ explains the process of writing appears to be 'inherently lonely' as it often takes place in a closed off space, away from others. Furthermore, Pilbeam and Denyer $(2009,303)$ argue that a 'sense of isolation may be an inherent feature of the doctoral student experience' as they are offered less institutional support and are expected to be 'independent learners'.

This study's findings suggest that these disparities can be attributed to a range of cultural and individual factors. Perhaps the most notable aspect of this study was the differences between doctoral students' experiences of digital technology use prior to starting their PhD. This can be justified because compared to undergraduate students doctoral researchers represent a more heterogeneous group with a wide range of ages, experiences and skills as well as a diverse set of research foci (Coverdale, Hill, and Sissons 2011). This was notable for the participants in this study who, despite their small number, presented great variations in age, digital know-how, confidence and cultural background. Similar to other studies, this heterogeneity was seen to influence their use of digital technology for their academic practice.

Furthermore, PhD students often lack homogeneity because of their 'diverse life experiences' (QAA 2015, 4) as well as their diverse cultural backgrounds which can 
lead to the formation of more segregated networks. For instance, face-to-face, email and social media networks were reported to emerge based on shared language and culture rather than shared research interests and this is in line with the findings of (Deem and Brehony 2000) who explained that '[w]here there are a number of students from the same country, locally based support groups do spring up’.

Notwithstanding the individual and cultural differences amongst students that can influence their mode of study there are also differences between the cultures of different academic disciplines or ‘academic tribes’ (Becher and Trowler 2001).This is particularly the case for social sciences, which is seen as a rather fragmented field as opposed to the natural sciences, which are characterised by more cohesive cultures (Pilbeam and Denyer 2009). In particular, undertaking a conventional $\mathrm{PhD}$ in the social sciences that involves conducting independent research and producing a long thesis suggests that students 'are only rarely part of a team or meaningful student cohort' and that 'their work can prove rather socially isolating' (Deem and Brehony 2000, 149-50). Additionally, the lone scholar aspect is highly pronounced for part-time students who do not spend much time in their departments and face more difficulties in becoming part of peer student cultures and academic cultures (ibid).

What also emerged from the data was that students often lacked the confidence, skills and experience to network and communicate their own research across wider academic audiences. Conversely to undergraduate and postgraduate taught programmes different communication and networking skillsets are required for $\mathrm{PhD}$ students. Additionally, the doctoral experience is not solely limited to the accumulation of relevant research skills but it is also a process of identity formation as a scholar in a chosen discipline. In becoming a researcher, $\mathrm{PhD}$ candidates need to 'negotiate new identities and reconceptualise themselves both as people and professionals' (Hall and 
Burns 2009, 1). Furthermore the development of a researcher identity during a $\mathrm{PhD}$ is a social undertaking (Mantai 2015) as well as a varied and complex process (Hancock and Walsh 2016).

All in all, doctoral students' experience of the 'digital university’ was not singular but was affected by a range of personal and cultural parameters. Although the majority of them appreciated the potential of digital technologies to support them with their studies, they felt they needed more institutional support in order to do this more effectively. This ranged from more advanced training tailored to their doctoral research field to support in developing a better understanding of how they could use social media more effectively. Additionally, students highlighted the value of face-to-face interaction with peers and suggested they should be provided with more opportunities for social and academic activities that would decrease their sense of isolation and would facilitate the formation of a physical and possibly digital doctoral community. As such, online engagement was welcomed as a follow-up to face-to-face events and activities.

In summary, doctorates are seen to demand a range of technical, communicative and other skills. Although institutions provide support and training regarding the development of research skills such as academic writing, data analysis etc other aspects of doctoral studies such as academic networking and development of a professional identity tend to be overlooked. As Danby and Lee $(2011,4)$ argue '[d]octoral education involves not just coming to know, that relates to acquiring relevant skills and expertise but also 'coming to be' - creating an identity as a researcher and scholar'. Students need to be supported towards achieving this and it should not be assumed that they are either familiar or competent with such practices. Additionally, since social engagement and networking are considered key aspects of the research journey, there is a pressing need 
for more effective ways of fostering students' 'active agency in scholarly communities' (Pyhältö, Stubb, and Lonka 2009, 230).

\section{Conclusion}

In the era of the 'digital university' (Goodfellow and Lea 2013), research into how doctoral students use digital technologies to support their studies, shape their online identities and engage in wider research networks is still at an emergent stage. Relatively little is yet known, or understood, about how doctoral students engage in such digital practices and what the enablers and barriers underpinning these are. This is important as digital technologies have the potential to support students with different aspects of their $\mathrm{PhD}$ and facilitate their journey towards becoming early-career academics. At the same time, social science research is seen to be beginning to move away from the model of the independent scholar towards the idea of collaborative research based around new, global networks (Green 2009). Additionally, ECR’s are increasingly expected by their institutions to have pre-established networks, seek collaborative funding opportunities and have self-promotion skills in order to get their work noticed and their voice heard.

This small-scale qualitative research study has only scratched the surface when it comes to identifying and understanding the range of complex issues surrounding doctoral students' use of digital technologies. It joins a slowly growing body of research in this field and in many respects one can argue that it has raised more questions than it has answered. When considering the results of this study, readers should be made aware of the limitations emerging from the small-scale nature of this research project and therefore generalizable conclusions should not be drawn. Indeed there are unavoidable gaps and issues that certainly merit further consideration and point to directions for further research that would involve a larger sample of participants across a range of academic fields. 
Notwithstanding the limitations of such small-scale qualitative studies with regard to generalizability, the following conclusions can be reached. As the findings of this study suggest, institutional support, guidance and training provided to doctoral students regarding digital scholarship practices is limited to more mundane aspects such as using relevant software for data collection and analysis and managing bibliographical references. Other aspects of digital scholarship such as creating an online identity and engaging in web-based research communities are rather overlooked and depend at large on guidance received from individual supervisors as well as peers. Moreover, this study has shown that there is a mismatch between how doctoral students experience academia and the expectations that they will encounter when and if they join academia as ECRs. To this end, more attention might be paid towards providing the space to $\mathrm{PhD}$ students not only to learn 'what it means to do research' but also to learn 'how to perform as a researcher' (Mantai 2015, 2). If doctoral students are to move beyond the largely, lone $\mathrm{PhD}$ journey reported in this paper and engage in more open, participatory and collaborative practices, then further institutional support needs to be provided in order to achieve this.

\section{References}

Baker, Vicki L., and Lisa R. Lattuca. 2010. 'Developmental Networks and Learning: Toward an Interdisciplinary Perspective on Identity Development during Doctoral Study'. Studies in Higher Education 35 (7): 807-27. doi:10.1080/03075070903501887.

Barnacle, Robyn, and Inger Mewburn. 2010. 'Learning Networks and the Journey of “becoming Doctor”’. Studies in Higher Education 35 (4): 433-44. doi:10.1080/03075070903131214.

Becher, Tony, and Paul Trowler R. 2001. Academic Tribes and Territories: Intellectual Enquiry and the Cultures of Disciplines. 2 edition. Philadelphia, PA: Open University Press.

Beetham, H., and Rhona Sharpe. 2010. 'Literacies Development Framework'. http://jiscdesignstudio.pbworks.com/w/file/40474958/Literacies\%20developmen t\%20framework.doc. 
Costa, Cristina. 2014. 'The Habitus of Digital Scholars'. Research in Learning Technology 21 (0). doi:10.3402/rlt.v21.21274.

Coverdale, Andy, LeRoy Hill, and Tracy Sissons. 2011. 'Using Social Media in Academic Practice: A Student-Led Training Initiative.' Compass: The Journal of Learning and Teaching at the University of Greenwich 3: 37-45.

Cumming, Jim. 2010. 'Doctoral Enterprise: A Holistic Conception of Evolving Practices and Arrangements'. Studies in Higher Education 35 (1): 25-39. doi:10.1080/03075070902825899.

Danby, Susan, and Alison Lee. 2011. 'Framing Doctoral Pedagogy as Design and Action'. In Reshaping Doctoral Education: International Approaches and Pedagogies, edited by Alison Lee and Susan Danby, 3-11. Milton Park, Abingdon, Oxon; New York: Routledge.

Deem, Rosemary, and Kevin J. Brehony. 2000. 'Doctoral Students' Access to Research Cultures-Are Some More Unequal than Others?' Studies in Higher Education 25 (2): 149-65. doi:10.1080/713696138.

Dunleavy. 2014. 'Are You an Academic Hermit? Here’s How to Easily Change, If You Want To.' Writing For Research. https://medium.com/advice-and-help-inauthoring-a-phd-or-non-fiction/are-you-an-academic-hermit6d7ae5a0f16a\#.dvl032vay.

Edmunds, Rob, Mary Thorpe, and Grainne Conole. 2012. 'Student Attitudes towards and Use of ICT in Course Study, Work and Social Activity: A Technology Acceptance Model Approach’. British Journal of Educational Technology 43 (1): 71-84. doi:10.1111/j.1467-8535.2010.01142.x.

Esposito, Antonella. 2014. "The Transition "from Student to Researcher" in the Digital Age: Exploring the Affordances of Emerging Learning Ecologies of PhD EResearchers'.

http://www.tesisenred.net/bitstream/handle/10803/290995/PhDdissertation_Esp ositoAE_Nov10.pdf?sequence $=1$ \&isAllowed $=\mathrm{y}$.

Flores-Scott, E., and M. Nerad. 2012. 'Flores-Scott, E. \& Nerad, M. (2012). Peers in Doctoral Education. , 157 (Spring 2012), 73-83.’ In New Directions For Higher Education. Vol. 157. Spring.

Goodfellow, Robin, and Mary R. Lea, eds. 2013. Literacy in the Digital University: Critical Perspectives on Learning, Scholarship and Technology. New York: Routledge.

Green, B. 2009. 'Challenging Perspectives, Changing Practices: Doctoral Education in Transition’. In Changing Practices of Doctoral Education, edited by D. Boud and A. Lee. London: Routledge.

Hall, Leigh Al, and Leslie Burns D. 2009. 'Identity Development and Mentoring in Doctoral Education'. Harvard Educational Review 79 (1): 49-70.

Hancock, Sally, and Elaine Walsh. 2016. 'Beyond Knowledge and Skills: Rethinking the Development of Professional Identity during the STEM Doctorate'. Studies in Higher Education 41 (1): 37-50. doi:10.1080/03075079.2014.915301.

Henderson, Michael, Neil Selwyn, and Rachel Aston. 2015. 'What Works and Why? Student Perceptions of “useful” Digital Technology in University Teaching and Learning'. Studies in Higher Education, February, 1-13. doi:10.1080/03075079.2015.1007946.

James, Laura, John Norman, Sophie De Baets, Ingrid Burchell-Hughes, Helen Burchmore, Amyas Philips, Dan Sheppard, Linda Wilks, and John Wolffe. 2009. 'Lives and Technologies of Early Career Researchers'. Cambridge: CARET, University of Cambridge. 
http://www.webarchive.org.uk/wayback/archive/20140614204612/http://www.ji

sc.ac.uk/publications/reports/2009/earlycareerresearchersstudy.aspx.

JISC. 2012. 'Researchers of Tomorrow: The Research Behaviour of Generation Y Doctoral Students'. London.

http://www.webarchive.org.uk/wayback/archive/20140614205429/http://www.ji sc.ac.uk/media/documents/publications/reports/2012/Researchers-ofTomorrow.pdf.

. 2014. 'Developing Digital Literacies’. Jisc. https://www.jisc.ac.uk/fullguide/developing-digital-literacies.

Lea, Mary R., and Barry Stierer. 2011. 'Changing Academic Identities in Changing Academic Workplaces: Learning from Academics’ Everyday Professional Writing Practices'. Teaching in Higher Education 16 (6): 605-16. doi:10.1080/13562517.2011.560380.

Lee, Alison, and Susan Danby, eds. 2011. Reshaping Doctoral Education: International Approaches and Pedagogies. Milton Park, Abingdon, Oxon; New York: Routledge.

Mantai, Lilia. 2015. 'Feeling like a Researcher: Experiences of Early Doctoral Students in Australia'. Studies in Higher Education, August, 1-15. doi:10.1080/03075079.2015.1067603.

Petre, Marian, Shailey Minocha, and Leonor Barroca. 2014. 'Digital Technologies for Doctoral Dialogues at a Distance’. In , 2432-39. Madrid, Spain. http://oro.open.ac.uk/40580/.

Pilbeam, Colin, and David Denyer. 2009. 'Lone Scholar or Community Member? The Role of Student Networks in Doctoral Education in a UK Management School'. Studies in Higher Education 34 (3): 301-18. doi:10.1080/03075070802597077.

Pilbeam, Colin, Gaynor Lloyd-Jones, and David Denyer. 2013. 'Leveraging Value in Doctoral Student Networks through Social Capital'. Studies in Higher Education 38 (10): 1472-89. doi:10.1080/03075079.2011.636800.

Pyhältö, Kirsi, Jenni Stubb, and Kirsti Lonka. 2009. 'Developing Scholarly Communities as Learning Environments for Doctoral Students’. International Journal for Academic Development 14 (3): 221-32. doi:10.1080/13601440903106551.

QAA. 2015. 'Characteristics Statement- Doctoral Degree'. QAA. http://www.qaa.ac.uk/en/Publications/Documents/Doctoral-DegreeCharacteristics-15.pdf.

Research Information Network. 2010. 'If You Build It, Will They Come? How Researchers Perceive and Use Web 2.0’. London: Research Information Network. http://www.rin.ac.uk/system/files/attachments/web_2.0_screen.pdf.

Stewart, Bonnie E. 2015. 'In Abundance: Networked Participatory Practices as Scholarship'. The International Review of Research in Open and Distributed Learning 16 (3). http://www.irrodl.org/index.php/irrodl/article/view/2158.

Valentín, Alberto, Pedro M. Mateos, María M. González-Tablas, Lourdes Pérez, Estrella López, and Inmaculada García. 2013. 'Motivation and Learning Strategies in the Use of ICTs among University Students'. Computers \& Education 61 (February): 52-58. doi:10.1016/j.compedu.2012.09.008.

Veletsianos, George. 2016. Social Media in Academia: Networked Scholars. New York: Routledge.

Veletsianos, George, and Royce Kimmons. 2012. 'Networked Participatory Scholarship: Emergent Techno-Cultural Pressures toward Open and Digital 
Scholarship in Online Networks’. Computers \& Education 58 (2): 766-74. doi:10.1016/j.compedu.2011.10.001.

. 2013. 'Scholars and Faculty Members' Lived Experiences in Online Social Networks'. The Internet and Higher Education 16 (January): 43-50.

doi:10.1016/j.iheduc.2012.01.004.

_ 2016. 'Scholars in an Increasingly Open and Digital World: How Do Education Professors and Students Use Twitter?' The Internet and Higher Education 30 (July): 1-10. doi:10.1016/j.iheduc.2016.02.002.

Vitae. 2011. 'Vitae Researcher Development Framework (RDF)'. File. https://www.vitae.ac.uk/vitae-publications/rdf-related/researcher-developmentframework-rdf-vitae.pdf.

Weller, Martin. 2011. The Digital Scholar: How Technology Is Transforming Scholarly Practice. London: Bloomsbury Academic. http://www.bloomsbury.com/uk/thedigital-scholar-9781849666268/.

Zhu, Yimei, and Rob Procter. 2012. 'Use of Blogs, Twitter and Facebook by PhD Students for Scholarly Communication: A UK Study (Manchester eScholar Services - The University of Manchester)'. In . Macao International Conference. https://www.escholar.manchester.ac.uk/item/?pid=uk-ac-man-scw:187789. 